\title{
Global COVID-19 Efforts as the Platform to Achieving the Sustainable Development Goals
}

\author{
Rojelio Mejia ${ }^{1}$ (D) Peter Hotez ${ }^{1,2,3,4,5,6,7} \cdot$ Maria Elena Bottazzi $i^{1,2,3,4}$ \\ Published online: 20 August 2020 \\ (C) Springer Nature Switzerland AG 2020
}

\begin{abstract}
Purpose of Review In this commentary, we summarize and put into perspective the recent information that highlights the associations between coronavirus disease and poverty. We also bring attention to another dimension that will most likely exacerbate the severity and long-term sequelae of COVID-19 in impoverished populations, that is, the comorbidities and the presence of tropical infections.

Recent Findings During this first half of 2020, the COVID-19 pandemic has emerged as a poverty-related neglected disease on at least two fronts. First, is its significant impact in low-income neighborhoods in the USA, the epicenter of the pandemic. Second, is its emergence in poor urban areas of South America, and now in Asia and Africa. In both fronts, the pandemic is contributing heavily towards the loss of public health gains that we managed to achieve globally during the last two decades. Specifically, any advances made as part of the United Nations Millennium Development Goals (United Nations, 2020) is eroding, and for the first time, the number of people entering extreme poverty is increasing. Adding to this descent into poverty are new disruptions in ongoing disease control programs, routine vaccination strategies, and a reduction of capacity building efforts globally. Therefore, and as highlighted by many others, we support the notion that a way forward to eliminate this coronavirus pandemic should include linking COVID-19 control to other tropical or poverty-related diseases.

Summary COVID-19 is slowing or reversing global health and development gains. To be successful and achieve the global goals including the control of pandemics such as the one seen from the COVID-19, we must rely on strong leadership leading to impactful public policies and global collaborations, including global COVID-19 vaccinations, and potentially linking them to programs for childhood and adult vaccinations and programs for malaria, tuberculosis, HIV/AIDS, and neglected tropical disease treatments. Opportunities also include the creation of unique research opportunities and funding models and increase science engagement for international diplomacy. This can only be done with a better understanding of the relationships between coronavirus disease, poverty, and tropical diseases.
\end{abstract}

Keywords Coronavirus $\cdot$ Poverty $\cdot$ COVID-19 $\cdot$ Pandemic

This article is part of the Topical Collection on Hot Topics in Tropical Medicine

Rojelio Mejia

rojelio.mejia@bcm.edu

1 Department of Pediatrics and Medicine, National School of Tropical Medicine, Baylor College of Medicine, Houston, TX, USA

2 Texas Children's Hospital Center for Vaccine Development, Houston, TX, USA

3 Departments of Pediatrics and Molecular Virology \& Microbiology, National School of Tropical Medicine, Baylor College of Medicine, Houston, TX, USA
4 Department of Biology, Baylor University, Waco, TX, USA

5 Hagler Institute for Advanced Studies, Texas A\&M University, College Station, TX, USA

6 Scowcroft Institute of International Studies, Bush School of Government and Public Service, Texas A\&M University, College Station, TX, USA

7 James A Baker III Institute of Public Policy, Rice University, Houston, TX, USA 


\section{Introduction}

The recent global pandemic caused by the novel severe acute respiratory syndrome coronavirus 2 (SARS-CoV-2) and its associated coronavirus disease (COVID-19) [1] has affected almost every country in the world [2].

The World Health Organization is closely tracking the rapid spread of COVID-19 throughout the world, with daily situation reports [3]. Table 1 shows a summary of the WHO's report of the total number of COVID-19 cases and the total number of COVID-19 deaths by region, taken from the last day of each month(March through July 2020). Increasingly, there is a recognition that COVID-19 is striking people living in poverty. This is happening on two fronts. Beginning with New Orleans in the spring of 2020, COVID-19 has caused significant devastation in low-income neighborhoods in US metro areas. African-American, Latino, and Native American populations living in these areas disproportionately account for the deaths and hospitalizations from COVID-19 [9]. In addition, now, COVID-19 is affecting Latin American nations, especially in poor urban areas - the favelas - of Brazilian metro areas, and increasingly India and adjacent countries in South Asia, and Africa. COVID-19 has spread into these regions and populations aided by weakened health systems with inadequate public health interventions leading to an increase in numbers of cases. We are already starting to see significant levels of mortality in Brazilian cities, with the expectation that large metro areas and mega-cities in India and Africa will follow.

\section{Entering the Americas Southern Hemisphere}

The initial entry of COVID-19 into the Southern Hemisphere is happening in Central and South America. Overwhelmingly, Brazil is the majorly affected country, especially in the favelas, the densely crowded slums of cities such as Sao Paulo, Rio de Janeiro, and Salvador de Bahia, but especially the northern tropical cities of
Belem, Fortaleza, and Manaus. Urban areas of Chile, Peru, and Ecuador are also affected, and COVID-19 is expected to become one of the most widespread virus infections in Latin America (Table 2). We also see significant levels of illness in Mesoamerica, referring to Mexico and Central America. Currently, Mexico has the highest case fatality rates in the Americas [10]. The Caribbean is also beginning to see significant levels of infection with Trinidad and Tobago exceeded only by Mexico for case fatality rates, according to the Pan American Health Organization.

For the past two decades, these countries within the Americas have confronted many health challenges mixed together with other political and socioeconomic hurdles [11]. Beyond efforts to implement public health control, there are concerns that affected populations will experience long-term disabilities due to pulmonary scarring, cardiovascular complications, and neurologic deficits [12], as well as other clinical manifestations still being discovered [13]. Accordingly, these virus-related morbidities will add to the many already found in these populations already affected by non-communicable diseases functioning as major risk factors for COVID-19, as well as other infections, including the neglected tropical diseases (NTDs). A recent article in the Public Library of Sciences Neglected Tropical Diseases Journal provides a complete description and list of what are the NTDs predominantly all found in these regions [14].

Now, COVID-19 is accelerating in India and elsewhere in South Asia. Estimates indicate that India could eventually exceed the USA or Brazil in terms of the total number of cases and deaths. There is an urgency to better understand the geographic distribution of India's COVID-19 epidemic, especially in terms of specifically affected urban areas. COVID-19 is also now affecting sub-Saharan Africa, beginning with South Africa and Egypt as the most affected countries. However, it is uncertain whether the relatively low number of cases across the region mostly reflects underreporting. For example, Tanzania has made claims to be unaffected by COVID-19 without external validation [15].

Table 1 A summary of the total numbers of cases and deaths in the different WHO regions

\begin{tabular}{llllll}
\hline WHO regions & \multicolumn{4}{l}{ Total cases (total deaths) } & \\
\cline { 2 - 5 } & March [4] & April [5] & May [6] & June [7] & July [8] \\
\hline Africa & $3786(77)$ & $24,713(938)$ & $100,610(2554)$ & $297,290(6010)$ & $770,421(13,234)$ \\
Americas & $163,014(2836)$ & $1,246,190(65,228)$ & $2,743,793(157,702)$ & $5,136,705(247,129)$ & $9,152,173(351,121)$ \\
Eastern Mediterranean & $50,349(2954)$ & $182,417(7447)$ & $505,001(12,353)$ & $1,058,055(24,423)$ & $1,533,357(39,661)$ \\
Europe & $423,946(26,694)$ & $1,434,649(135,961)$ & $2,142,547(180,085)$ & $2,692,086(197,254)$ & $3,333,300(212,520)$ \\
South east Asia & $4215(166)$ & $54,021(2088)$ & $260,579(7431)$ & $784,931(21,593)$ & $2,009,963(44,031)$ \\
Western Pacific & $104,868(3671)$ & $147,743(6094)$ & $181,665(7028)$ & $215,566(7440)$ & $306,052(8330)$ \\
\hline
\end{tabular}


Table 2 A summary of the total numbers of cases, deaths, and recovered in the different subregions of the Americas

\begin{tabular}{lllll}
\hline \multirow{2}{*}{ Sub region } & \multicolumn{2}{l}{ Total cases (total deaths)* } \\
\cline { 2 - 5 } & Number of countries & Cumulative cases & Cumulative deaths & Cumulative recovered \\
\hline North America & 3 & $5,355,899$ & 216,017 & $1,984,265$ \\
Central America & 7 & 212,563 & 5924 & 112,009 \\
South America & 10 & $4,445,110$ & 152,687 & $3,057,235$ \\
Caribbean & 34 & 121,750 & 1978 & 59,154 \\
\hline
\end{tabular}

*https://paho-covid19-response-who.hub.arcgis.com/ (accessed August 7, 2020)

\section{The USA}

Like many of the NTDs, COVID-19 has disproportionally targeted the most impoverished populations in high-income regions around the world [2]. The concept of blue marble health refers to the "poorest of the rich" in nations such as the USA [16]. A recent US study revealed that in the early stages of the pandemic, the populations living in the most underserved communities had higher rates of deaths due to COVID-19, compared with affluent locations [17]. Initial thoughts hypothesized that these findings could be primarily due to a lack of access to testing in these communities. But it also gave clarity that these underserved communities found themselves at a serious disadvantage since the start of the pandemic. Social distancing is typically difficult in crowded households in low-income neighborhoods, where many do not have the opportunities to work from home. These poor populations generally have pre-existing health conditions due to inadequate access to high-quality healthcare. Among them are high rates of obesity, diabetes, and cardiovascular disease.

As is expected, of course, this also occurs in many areas around the world, especially in populations living in low- and middle-income countries (LMICs). In Brazil, for instance, a study evaluating the vulnerabilities and deprivations of their populations has identified several main factors contributing to this effect: hygiene, shelter, physical distance, and health recovery capacity [18].

\section{Poverty as the Common Denominator}

The basis by which poverty functions as a risk factor for COVID-19 requires further investigation. SARS-CoV-2 uses a respiratory route of infection, associated with droplet contact and possibly airborne transmission, and therefore, population density is known to have large adverse effects [19]. It is very common that those who fall within low socioeconomic strata and/or live below the poverty level [20] generally have several generations living under a single household. Therefore, living in close quarters with multiple inhabitants means direct contact with commonly used items; it can increase the risk of being exposed to the virus. In urban settings, additional factors that can lead to overcrowding may be the result of high rental costs, leading to families having to live in multi-family buildings and apartments [21].

The economic downturn due to social distancing and decreased consumption of products and services has further disproportionally affected the poor. People living in poverty generally have less access to health communication on cable news networks or post-secondary education, working hourly positions that are more at the mercy of recessions. Since they do not maintain a standard salary, many people in poverty need to continue working hourly jobs and place themselves at risk from public exposure with COVID-19.

Other factors can influence COVID-19 morbidity and death, including age and non-communicable comorbidities such as diabetes, pulmonary, heart, or other organ-related diseases [22, 23]. This, in turn, can feedback and influence the high levels of transmission of SARS-CoV-2 seen in these populations contributing to the observed epidemiology of COVID-19 within these populations [19]. Individuals with low socioeconomics also have higher comorbidities that come from poor nutrition and the lack of access to primary medical services. Health care is difficult to receive for people living below the poverty level. In both urban and rural settings, there is both a lack of accessible clinics for primary care and also a lack of insurance or the capacity to pay for preventive medical care. Higher rates of smoking and alcohol consumption are also prevalent in both urban and rural people living in poverty. Obesity, for instance, is associated with low-income populations, usually from consuming foods high in fats and carbohydrates that are still affordable. Diabetes is also a significant problem that can be related to obesity. Diabetes can severely impact the immune response of a person. All these health comorbidities can be the difference between asymptomatic COVID-19 infection and intubated in the intensive care unit.

\section{COVID-19 and its Relationship with Tropical Diseases}

There is increasing evidence that tropical diseases are also causative for propagating poverty in those infected [24]. In 
the USA, an urban study in New York City reported a direct correlation with more Toxocara parasite in city parks from poor neighborhoods compared with rich boroughs [25]. Another study in a clinic that serves low-income patients located in Washington D.C. was found to have endemic levels of a potentially dangerous parasite called Strongyloides stercoralis in this low-income population [26]. A third study done in Chicago found evidence of both Toxocara and Strongyloides in this urban population [27]. Major US cities had high levels of COVID-19 infections and a higher prevalence in those living below the poverty line [28].

For rural areas in the USA, there are studies in Alabama that show hookworm (Necator americanus), and Strongyloides stercoralis is still present and transmitting in the population of poor rural Alabama [24]. In Texas, a study detected $16.5 \%$ of people infected with Strongyloides stercoralis from a poor area outside of Austin, TX, that has limited sanitation facilities [29]. COVID-19 has also been prevalent in the Southern USA [21].

\section{Linking COVID-19 to NTD Control}

Given the dire public health crisis created by the emergence of COVID-19, it is anticipated that global resources will be committed to disease control and prevention. As for funds for the COVID-19 vaccination scale, it will be interesting to look at opportunities to bundle these efforts for other tropical infections. For example, adult vaccinations for COVID-19 could be linked to scale-up for other adult vaccines, including influenza. As new vaccines for schistosomiasis and Chagas disease enter advanced development, there may be opportunities to link these as well [30]. Outside of vaccines, we will need to look at bundling COVID-19 vaccines with mass treatments for malaria, tuberculosis, and HIV/AIDS, as well as largescale programs for neglected tropical diseases. Until then, there are concerns that calls for social distancing might interrupt existing programs. There remains the possibility that we might see a resurgence in HIV/AIDS, tuberculosis, and malaria, and neglected tropical diseases. We have also seen how childhood vaccination programs for measles and other conditions were interrupted in the USA during the spring of 2020 [31]. We may face similar interruptions in global child vaccination programs led by Gavi, the Vaccine Alliance.

\section{Concluding Statement}

The poor living in urban or rural areas of high-income countries and the most impoverished living in LMICs have increased risk for both COVID-19 and tropical diseases. These combinations disproportionally affect the working poor, both in health and economically, as to suffer long-term setbacks from missing work. The year 2020 is notable for the extraordinary global spread of COVID-19 and the interruptions in key public health programs for both neglected diseases and vaccine-preventable diseases. We face the potential for a slowing, halting, or even reversal of all of the amazing gains since the launch of the 2000 Millennium Development Goals. Given the anticipated support for COVID-19 vaccinations globally, it would seem wise to look at how some of the lapsed interventions could be resurrected and bundled.

\section{Compliance with Ethical Standards}

Conflict of Interest Maria Elena Bottazzi and Peter Hotez are inventors of a low-cost COVID-19 vaccine for global health which was recently licensed by Baylor College of Medicine to a commercial third party for scale up and production.

Human and Animal Rights and Informed Consent This article does not contain any studies with human or animal subjects performed by any of the authors.

\section{References}

1. World Health Organization. Naming the coronavirus disease (COVID-19) and the virus that causes it. 2020. https://www.who. int/emergencies/diseases/novel-coronavirus-2019/technicalguidance/naming-the-coronavirus-disease-(covid-2019)-and-thevirus-that-causes-it. Accessed July 6, 2020.

2. Walker PGT, Whittaker C, Watson OJ, Baguelin M, Winskill P, Hamlet A, et al. The impact of COVID-19 and strategies for mitigation and suppression in low- and middle-income countries. Science. 2020:eabc0035. https://doi.org/10.1126/science.abc0035.

3. World Health Organization. Coronavirus disease (COVID-19) situation reports. 2020. https://www.who.int/emergencies/diseases/ novel-coronavirus-2019/situation-reports. Accessed July 6, 2020.

4. World Health Organization. Coronavirus disease 2019 (COVID19) situation report-71, 2020. Available from: https://www.who. int/docs/default-source/coronaviruse/situation-reports/20200331sitrep-71-covid-19.pdf?sfvrsn=4360e92b_8. Accessed July 6, 2020.

5. World Health Organization. Coronavirus disease 2019 (COVID19) situation report-101, 2020. Available from: https://www.who. int/docs/default-source/coronaviruse/situation-reports/20200430sitrep-101-covid-19.pdf?sfvrsn=2ba4e093_2. Accessed July 6, 2020.

6. World Health Organization. Coronavirus disease (COVID-19) situation report-132, . Available from: https://www.who.int/docs/ default-source/coronaviruse/situation-reports/20200531-covid-19sitrep-132.pdf?sfvrsn=d9c2eaef_2. Accessed July 6, 2020.

7. World Health Organization. Coronavirus disease (COVID-19) situation report-162, 2020. Available from: https://www.who.int/ docs/default-source/coronaviruse/20200630-covid-19-sitrep-162. pdf?sfvrsn=e00a5466 2. Accessed August 7, 2020.

8. World Health Organization. Coronavirus disease 2019 (COVID19) situation report-193. Available from: https://www.who.int/ docs/default-source/coronaviruse/situation-reports/20200731covid-19-sitrep-193.pdf?sfvrsn=42a0221d_4. Accessed August 7, 2020.

9. Centers for Disease Control. COVID-19 in racial and ethnic minority groups. 2020. https://www.cdc.gov/coronavirus/2019-ncov/ 
need-extra-precautions/racial-ethnic-minorities.html. Accessed July 5, 2020.

10. Pan American Health Organization. Americas region COVID-19 dashboard. 2020. https://who.maps.arcgis.com/apps/dashboards/ efb745c3d88647779beccb91c0e715f9. Accessed July 6, 2020.

11. Hotez PJ, Damania A, Bottazzi ME. Central Latin America: two decades of challenges in neglected tropical disease control. PLoS Negl Trop Dis. 2020;14(3):e0007962. https://doi.org/10.1371/ journal.pntd.0007962.

12. Hotez PJ, Bottazzi ME, Singh SK, Brindley PJ, Kamhawi S. Will COVID-19 become the next neglected tropical disease? PLoS Negl Trop Dis. 2020;14(4):e0008271. https://doi.org/10.1371/journal. pntd.0008271.

13. Rodriguez-Morales AJ, Rodriguez-Morales AG, Mendez CA, Hernandez-Botero S. Tracing new clinical manifestations in patients with COVID-19 in Chile and its potential relationship with the SARS-CoV-2 divergence. Curr Trop Med Rep. 2020;7:1-4. https://doi.org/10.1007/s40475-020-00205-2.

14. Hotez PJ, Aksoy S, Brindley PJ, Kamhawi S. What constitutes a neglected tropical disease? PLoS Negl Trop Dis. 2020;14(1): e0008001. https://doi.org/10.1371/journal.pntd.0008001.

15. BBC News. Tanzania' free of coronavirus'-president. 2020.

16. Hotez PJ. Poverty and the impact of COVID-19: the blue-marble health approach: Johns Hopkins University Press; 2020.

17. Finch WH, Hernández Finch ME. Poverty and Covid-19: rates of incidence and deaths in the United States during the first 10 weeks of the pandemic. Front Sociol. 2020;5(47). https://doi.org/10.3389/ fsoc.2020.00047.

18. Tavares FF, Betti G. Vulnerability, poverty and COVID-19: risk factors and deprivations in Brazil. Researchgate, 2020. Available from: https://www.researchgate.net/publication/340660228 Vulnerability_Poverty and_COVID-19_Risk_Factors_and Deprivations in Brazil. Accessed July 6, 2020.

19. Abedi V, Olulana O, Avula V, Chaudhary D, Khan A, Shahjouei S, et al. Racial, economic and health inequality and COVID-19 infection in the United States. medRxiv. 2020. https://doi.org/10.1101/ 2020.04.26.20079756.

20. Office of the Assistant Secretary for Planning and Evaluation. Poverty guidelines. 2020. https://aspe.hhs.gov/poverty-guidelines. Accessed July 6, 2020.

21. Zhang $\mathrm{CH}$, Schwartz GG. Spatial disparities in coronavirus incidence and mortality in the United States: an ecological analysis as of May 2020. J Rural Health. 2020;36:433-45. https://doi.org/10. 1111/jrh.12476.

22. Wang T, Du Z, Zhu F, Cao Z, An Y, Gao Y, et al. Comorbidities and multi-organ injuries in the treatment of COVID-19. Lancet. 2020;395(10228):e52. https://doi.org/10.1016/S0140-6736(20) 30558-4.
23. CDC Covid-19 Response Team. Severe outcomes among patients with Coronavirus disease 2019 (COVID-19) - United States, February 12-March 16, 2020. In: Weekly mortality and mortality report 2020. https://www.cdc.gov/mmwr/volumes/69/wr/ mm6912e2.htm\#contribAff. Accessed July 6, 2020.

24. McKenna ML, McAtee S, Bryan PE, Jeun R, Ward T, Kraus J, et al. Human intestinal parasite burden and poor sanitation in rural Alabama. Am J Trop Med Hyg. 2017;97(5):1623-8. https://doi. org/10.4269/ajtmh.17-0396.

25. Tyungu DL, McCormick D, Lau CL, Chang M, Murphy JR, Hotez $\mathrm{PJ}$, et al. Toxocara species environmental contamination of public spaces in New York City. PLoS Negl Trop Dis. 2020;14(5): e0008249. https://doi.org/10.1371/journal.pntd.0008249.

26. Ostera G, Blum J, Cornejo C, Burgula S, Jeun R, Bryan PE, et al. Strongyloidiasis in Latin American immigrants: a pilot study. J Helminthol. 2017;91(2):262-6. https://doi.org/10.1017/ S0022149X16000213.

27. Herrick JA, Nordstrom M, Maloney P, Rodriguez M, Naceanceno $\mathrm{K}$, Gallo $\mathrm{G}$, et al. Parasitic infections represent a significant health threat among recent immigrants in Chicago. Parasitol Res. 2020;119(3):1139-48. https://doi.org/10.1007/s00436-020-066084.

28. Goyal P, Choi JJ, Pinheiro LC, Schenck EJ, Chen R, Jabri A, et al. Clinical characteristics of Covid-19 in New York City. N Engl J Med. 2020;382(24):2372-4. https://doi.org/10.1056/ NEJMc2010419.

29. Singer R, Xu TH, Herrera LNS, Villar MJ, Faust KM, Hotez PJ, et al. Prevalence of intestinal parasites in a low-income Texas community. Am J Trop Med Hyg. 2020;102(6):1386-95. https://doi. org/10.4269/ajtmh.19-0915.

30. Bottazzi ME, Hotez PJ. "Running the Gauntlet": formidable challenges in advancing neglected tropical diseases vaccines from development through licensure, and a "Call to Action". Hum Vaccin Immunother. 2019;15(10):2235-42. https://doi.org/10.1080/ 21645515.2019.1629254.

31. Centers for Disease Control. Effects of the COVID-19 pandemic on routine pediatric vaccine ordering and administration-United States. In: Morbidity and mortality weekly report. 2020. https:// www.cdc.gov/mmwr/volumes/69/wr/mm6919e2.htm. Accessed July 6, 2020.

32. United Nations. About the sustainable development goals. 2020. https://www.un.org/sustainabledevelopment/sustainabledevelopment-goals/. Accessed July 5, 2020.

Publisher's Note Springer Nature remains neutral with regard to jurisdictional claims in published maps and institutional affiliations. 